\title{
Membangkitkan Sikap Kebangsaan di Pendidikan Teologi: Dimanakah kita berpijak?
}

\author{
Halim Wiryadinata \\ Sekolah Tinggi Teologi Pelita Bangsa, DKI Jakarta \\ ketua@sttpb.ac.id
}

\begin{abstract}
Theological education institutions in Indonesia are part of the complex component of this nation in the framework of progress and unity, which have roles and responsibilities in various national issues. Schools of theology, or Christian religion, do not only focus on producing outputs that will develop church services, especially internally, but also in the context of national life, both socially and even politically. Through church discourse and nationalism, this article aims to contribute ideas on how theological educational institutions should take up space to play a role in the locus of nationalism.
\end{abstract}

Keywords: church; nationalism; theological education; theological institution

\begin{abstract}
Abstrak: Institusi pendidikan teologi di Indonesia merupakan bagian dari komponen kompleks bangsa ini dalam bingkai kemajukan dan persatuan, yang memiliki peran dan tanggung jawab dalam berbagai persoalan kebangsaan. Sekolah-sekolah teologi, atau keagamaan Kristen, tidak hanya berfokus pada menghasilkan output yang akan mengembangkan pelayanan gereja, terlebih secara internal, melainkan juga dalam konteks kehidupan berbangsa, baik secara sosial, bahkan hingga politis. Melalui diskursus gereja dan nasionalisme, artikel ini bertujuan untuk menyumbangkan pemikiran, bagaimana seharusnya institusi pendidikan teologi mengambil ruang untuk berperan dalam lokus nasionalisme.
\end{abstract}

Kata kunci: gereja; institusi teologi; kebangsaan; pendidikan teologi

\section{Pendahuluan}

Pendidikan teologi adalah sebuah upaya memperlengkapi orang yang terpanggil olehNya melayani pekerjaan - pekerjaan-Nya di muka bumi. Memperlengkapi hamba - hambaNya melalui pendekatan - pendekatan secara teologis untuk menghasilkan sebuah interpretasi dengan berpegang teguh pada Kitab Suci dalam setiap pelayanan mereka. ${ }^{1}$ Pendidikan teologi terus berupaya menjalankan manajemen pendidikan yang terfokus pada konsep ideologi, yaitu penjangkauan manusia dalam bingkai misiologi. Dengan kata lain, pendidikan teologi lebih senang berada didalam zona 'interpretasi' ayat dan Kitab Suci dalam menghasilkan ideologi, bahkan terus berdebat pada tataran ide.

Perdebatan diranah teologis telah membuang kesempatan untuk menempatkan teologi menjadi kontributor bagi masalah - masalah sosial. Teologi sering kali "menyalahkan" keadaan dunia serta mengkritik keadaan sosial masyarkat, tanpa memberikan solusi. Hal ini membuat pertentangan antara keilmuan sosiologi dan teologi menjadi panjang bahkan menempatkan

${ }^{1}$ J. Banawiratma, J. B., dan Muller, Berteologi Sosial Lintas Ilmu (Yogyakarta: Kanisius, 1993); J. B. Banawiratma, 10 Agenda Pastoral Transformatif (Yogyakarta: Kanisius, 2002). 
keilmuan yang mana lebih unggul dari satu dengan yang lainnya. ${ }^{2}$ John Milbank menempatkan bahwa teologi tidak dapat bersatu dengan sosiologi, karena teologi dan sosiologi mempunyai konsep masing - masing. ${ }^{3}$ Dengan kata lain, Milbank menyatakan bahwa keilmuan teologi berada di atas dari keilmuan sosiologi. Hal ini, disisi yang lain, ditentang oleh Talcott Parson saat ia menyatakan bahwa teologi adalah partisipasi pasif yang dimana sosiologi adalah yang aktif dalam melihat realita. ${ }^{4}$ Kedua hal ini memberikan pandangan bahwa teologi dan sosiologi tidak dapat 'berdamai' bahkan memberikan ruang yang lebar untuk dipersatukan. Oleh karena itu, pendidikan teologi diberikan kesempatan untuk merefleksikan diri untuk berpijak dalam membangkitkan sikap kebangsaan.

Karya David Martin ${ }^{5}$ memberikan jalan perdamaian antara sosiologi dan teologi. Martin memahami bahwa Milbank melihat sosiologi dan teologi dari sisi philosophical worldview, karena setiap keilmuan memiliki pendekatan yang berbeda. Sosiologi adalah rationalis, sedangkan teologi yaitu empiris. ${ }^{6}$ David Martin memilih jalan dengan menekankan fungsi masing - masing keilmuan melalui model operasi keilmuannya. ${ }^{7}$ Oleh karena itu, tulisan ini mencoba melakukan pendekatan sosiologi untuk membangkitkan sikap kebangsaan di pendidikan teologi dengan tiga bagian, yaitu: pertama, melihat model operasi ilmu pengetahuan alami (natural science) dan ilmu budaya (cultural science). Kedua, mengembangkan pendidikan teologi di ranah sosial. Ketiga, mengembangkan pendidikan teologi sebagai kontributor sikap kebangsaan.

\section{Natural Science dan Cultural Science}

Max Weber ${ }^{8}$, menurut David Martin, melihat 'religious rejections' (penolakan keagamaan) tentang 'dunia' yang di tinjau dari sisi keberadaan sosial. ${ }^{9}$ Sedangkan, Weber menolak ide tentang dunia atas dasar kepercayaannya pada kekristenan saat ia melihat dominasi dunia yang terdiri dari kekuasaan, kekayaan, status sosial, sex dan kekejaman. Dominasi ini ditentang oleh Weber sebagai ketidakpuasan dalam sosiologi, politik, kerjasama internasional dan biologi. ${ }^{10}$ Kondisi ini menciptakan sebuah pertentangan antara sosiologi dan teologi, karena sosiologi melihat perbedaan kondisi sosial sedangkan teologi mempunyai harapan keagaaman. Hal ini menuntun Milbank pada presuposisi tentang bahayanya proses sekularisasi yang berhubungan dengan proses modernisasi tanpa suatu pertanyaan secara intelektual. Menurut

${ }^{2}$ John Milbank, Theology and The Social Theory, 2nd ed., vol. 66 (Oxford: Blackwell Publishing, 2006); Kieran Flanagan, "Sublime Policing: Sociology and Milbank's City of God," New Blackfriars 73, no. 861 (1992): 333-341; Hans Joas, "Social Theory and the Sacred: A Response to John Milbank," Ethical Perspectives 7, no. 4 (2000): 233-243.

${ }^{3}$ John Milbank, Theology and The Social Theory, 66:11.

${ }^{4}$ Talcott Parsons, "Social Science and Theology," in America and the Future of Theology, ed. William A. Beardslee (Philadelphia, 1967), 136-157. 175.

${ }^{5}$ David Martin, "Sociology and Theology: With and Agaisnt the Grain of 'the World'" 18, no. 2 (2015): 159-

${ }^{6}$ Frank B. Farrell, Empiricism and Theology, How Theology Shaped Twentieth-Century Philosophy, 2019; Demian Wheeler, "American Religious Empiricism and the Possibility of an Ecstatic Naturalist Process Metaphysics," Journal for the Study of Religion, Nature and Culture 8, no. 2 (2014): 156-181; Chul Min Jun, "The Paradigm Shift of Practical Theology and Theological Practice to Overcome Modernism and Postmodernism," Pacific Science Review 16, no. 2 (2014): 156-166, http://dx.doi.org/10.1016/j.pscr.2014.08.028.

${ }^{7}$ Martin, "Sociology and Theology: With and Agaisnt the Grain of 'the World.'"

${ }^{8}$ Max Weber, The Protestant Ethic and the Spirit of Capitalism, The Protestant Ethic and the Spirit of Capitalism, 2005; Max Weber, The Theory of Social and Economic Organization (New York: Free Press, 1947).

${ }^{9}$ (Martin, 2015, 159 - 175)

${ }^{10}$ Inger Furseth and Pål Repstad, An Introduction to the Sociology of Religion: Classical and Contemporary Perspectives, Ashgate Publishing Limited, 1st ed. (England: Ashgate Publishing Limited, 2013). 
Milbank, proses sekularisasi dalam fungsinya membentuk dunia baru yaitu de - sakralisasi politik dan de - saklarisasi agama kedalam sebuah proses institutionalisasi. ${ }^{11}$ Ini membuat Milbank menulis dengan jelas bahwa, "The secular as a domain has to be instituted or imagined, both in theory and in practice. This institution is not correctly grasped in merely negative terms as a desacralization." ${ }^{12} \mathrm{Hal}$ ini membuat teologi khawatir tentang sekuralisasi pada agama dan pemahaman ajaranya.

Kekhawatiran Milbank, Weber dan David Martin sangat jelas dilihat dari pengharapan teologi dalam merefeksikan ide sebuah kota di tulisan Augustine of Hippo ${ }^{13}$, Kota Allah dan Kota Manusia (The City of God and The City of Man), dan penolakan realitias sosial dan keteraturan sosial (social order) yang dilihat dari sisi sosiologi. ${ }^{14}$ Penolakan atas keteraturan sosial yang disebut oleh David Martin yaitu 'the grain of the world', karena agama menyajikan ide Kota Allah melalui bahasa manusia (human's language) dalam diskursus kenyamanan, universalitas, pengurbanan diri, pelayanan, pertobatan, dan rekonsiliasi. ${ }^{15}$ Oleh sebab itu, agama, khususnya pendidikan teologi, harus mentransformasi 'keberaturan sosial' (Kota Allah) ke Kota manusia sebagai harapan orang Kristen untuk mencapai kedamaian dan kesatuan sebagai nilai - nilai keagaamaan dalam membangkitkan sikap kebangsaan.

Secara teoretis dan empiris, kedisplinan ilmu budaya (cultural science) adalah struktur logika meskipun berbeda dengan kedisplinan ilmu pengetahuan alami (natural science), tetapi kedua keilmuan tersebut melibatkan naratif dan naratif itu sendiri melibatkan kemungkinan dan subyektivitas. ${ }^{16}$ Dengan kata lain, ilmu teologi dan sosiologi adalah keilmuan kultural, karena teologi dan sosiologi adalah kumulatif dan mengunjungi kembali pada text masing - masing untuk menginterprestasi realita. Oleh sebab itu karya Machiavelli, ${ }^{17}$ The Prince, ketika ia mendeskripsikan komunitas universal, dua atau tiga orang, adalah komunitas yang memiliki realitas yang dapat dipraktikan dalam waktu yang lama tanpa diartikulasikan. Dengan demikian, hal ini sama dengan teologi, karena teologi bukan hanya menceritakan kebenaran, tetapi teologi menawarkan sesuatu untuk diceritakan.

Memahami sebuah kenyataan (realita) dalam ilmu budaya (cultural science) yaitu menformulasikan realita dalam deskripsi dan referensi, empiris dan moral, apa yang harus dan apa yang sebenarnya. Oleh sebab itu, ilmu budaya menggabungkan perspektif moral dalam menilai sebuah aksi melalui perspektif etika. Moral etika membuat sosiologi sebagai ilmu kritis atas keperluan manusia. ${ }^{18}$ Berdasarkan pemahaman tersebut, maka entitas sosiologi dan teologi bukan permasalahan lokasi, tetapi permasalahan atas perbedaan antara apa yang ditulis dan subjek apa yang ditransformasi - selama sosiologi dan teologi kembali kepada buku buku kanonis untuk menginterpretasikan realita tersebut. Dengan perkataan lain, sosiologi dan teologi mempunyai kesamaan pandangan melihat konsep yang transenden, tetapi mereka berbeda dalam menyusun kenyataan atau pemberian realita dan memahami sesuatu yang bisa ditransendenkan atau ditransformasikan. Jika keyakinan dalam ilmu pengetahuan alami (natural science) adalah filosofis daripada ilmiah, lalu ilmu pengetahuan alami (natural science) selalu

\footnotetext{
${ }^{11}$ John Milbank, Theology and The Social Theory, 66:9.

${ }^{12}$ Ibid.

${ }^{13}$ Augustine of Hippo and Henry Bettlenson, The City of God (The United Kingdom: Penguin Classics, 2004).

${ }^{14}$ Flanagan, "Sublime Policing: Sociology and Milbank's City of God."

${ }^{15}$ Martin, "Sociology and Theology: With and Agaisnt the Grain of 'the World.'"

${ }^{16}$ Ibid.

${ }^{17}$ Niccolo Machiavelli, The Prince (Indianapolis: Hackett Pub. Co, 2008).

${ }^{18}$ Oliver O'Donovan, "Preference; Ought," Studies in Christian ethics 2, no. 1 (1990): 80-86.
} 
berhubungan dengan varian positivisme. Hal ini membuat model ilmu budaya (cultural science) termasuk sosiologi dan teologi dalam perspektif positivisme. ${ }^{19}$ Perangkulan ilmu budaya (cultural science) pada positivisme membawa teologi kedalam ilmu budaya untuk melihat realitas itu sendiri dan memberikan kontribusi pada Kota Manusia.

\section{Pendidikan Teologi di Ranah Sosial}

Berdasarkan pemahaman diatas, maka pendidikan teologi memiliki opsi yaitu merangkul atau menolak tentang kekejaman dunia. Dengan kata lain, menentukan penerimaan atau penolakan dunia atas kekuasaan dan kekejaman diranah sosial harus didasari kekuatan visi Kristen pada Kota Allah dan realitas dari kondisi manusia di bumi. Ini adalah 'sudut pandang' yang menjadi pertentangan yang transenden (Kristen) dan pertentangan yang dipahami sebagai kenyataan atas kekejaman dunia. Namun, Kota Allah mempunyai dimensi iman yang memberikan kebebasan dan keluasaan untuk mengangkat kenyataan (kekuasaan, kekayaan, status sosial, sex serta kekejaman) serta tersingkirnya pendidikan teologi di sosial - budaya. ${ }^{20}$

Pendidikan teologi sebaiknya merefleksikan konsep perayaaan ekaristi secara Kristen yaitu penggambarkan jalinan persaudaraan sebagai cita - cita perjuangan Yesus untuk mendeklarasikan bahwa tidak ada yang terlantar, yang acuh tak acuh, tidak ada yang dihisap dan yang menghisap, tetapi pembebasan kesamaan derajat ditingkat sosial - budaya. ${ }^{21} \mathrm{Hal}$ ini yang dikutip oleh David Martin saat melakukan interpretasi dari sudut pandang George Herbet, The Temple, karena didalam Ekaristi terjadi sebuah komuni antara kenyataan dan pemberian. Dengan kata lain, cinta kasih ekaristi di ibadah sebenarnya mempresentasikan dua entitas yaitu institusi yang superior dari komuni manusia dan keberadaan ilahi menjadi iman yang diindentifikasikan sebagai 'tanda kesatuan.' ${ }^{22}$ Dua entitas, transenden dan realita sosial (kekayaan, kekuasaan dan kekejaman), adalah kondisi ideal di perayaan Perjamuan Kudus untuk merehabilitasi sebuah komuni. Dengan meminjam kata Sarah Beckwith ${ }^{23}$ sebagai "the grammar of forgiveness."

Pendidikan teologi tidak bisa menghindar bahwa sosiologi dimengerti sebagai bagian dari modernisasi untuk menginterpretasi arti sebuah agama dan menggantikan sebagai ideologi atas pengekangan keimanan atau irasional imaginasi dalam dunianya atau mereduksi konsep keimanan kedalam refleksi realitas. Meskipun sosiologi melemahkan iman agama, tetapi membuat teologi secara signifikan sebagai keilmuan yang memahami realita daripada menjelaskan realita. Oleh karena itu, sosiologi tidak dapat menggantikan teologi - sebaliknya termasuk pemahaman imaginasi atau menggantikan penjelasan teologi atas mitos sebagai alasan yang abstrak. ${ }^{24}$ Jika dua entitas ini berdiri atas pemahaman cultural science, maka teologi dan sosiologi mempunyai kesamaan, karena teologi dan sosiologi sebagai mediasi antara jurang pemisah antara yang nyata dan yang ideal melalui pendekatan transformasi visioner. Suwarto $\mathrm{Adi}^{25}$ mengkombinasikan ide pendekatan antropologi untuk merefleksikan perspektif teologis dan memberikan ide tentang liyan dalam memperkenalkan keilmuan yang lain untuk melihat realita. Dengan kata lain, teori sosial sangat membantu teologi untuk

\footnotetext{
${ }^{19}$ Martin, "Sociology and Theology: With and Agaisnt the Grain of 'the World.'"

${ }^{20}$ Banawiratma, J. B., dan Muller, Berteologi Sosial Lintas IImu.

${ }^{21}$ Banawiratma, 10 Agenda Pastoral Transformatif.

${ }^{22}$ Martin, "Sociology and Theology: With and Agaisnt the Grain of 'the World.'"

${ }^{23}$ Sarah Beckwith, Shakespeare and the Grammar of Forgiveness (Ithaca New York: Cornell University Press,

${ }^{24}$ Martin, "Sociology and Theology: With and Agaisnt the Grain of 'the World.'"

${ }^{25}$ Suwarto Adi, Jalan Licin Penelitian Lapangan (Menggabungkan Antropologi Dan Teologi) (Salatiga, 2019).
} 2011). 
mengerti yang transenden menjadi imanen. Ini bukan melakukan sekularisasi dalam perspektif sosial atau ilmu budaya, melainkan menciptakan antroplogi etis yang mengandung nilai - nilai budaya.

Pendekatan transformasi visioner memberikan ruang pendidikan teologi bekerja dengan menggunakan bahasa 'tanda' seperti menggubah air menjadi anggur pada pesta pernikahan atau distribusi makanan kepada ribuan orang sebagai karakteristik tansformasi ketika iman yang dipraktikan untuk menghadapi sebuah realita dari kekuatan atau kekejian Kota Manusia. Oleh sebab itu, jurang pemisah antara realis dan empiris dapat dipertemukan dengan melakukan transformasi atau rekonsiliasi dengan keberadaan ilahi di dunia yang penuh realita.

Oleh sebab itu, pendidikan teologi sebaiknya menggabungkan keadaan realita di dunia dengan melakukan pendekatan transformasi visioner untuk memberikan manfaat untuk membangun sikap kebangsaan. Dengan kata lain, pendidikan teologi, seperti dikatakan oleh Agustine sebagai Kota Allah, harus mendarat dengan transformasi visoner pada realita - realita di Kota Manusia sehingga Pendidikan teologi memberikan manfaat. Hal ini membentuk fungsi pendidikan teologi sebagai pendidikan yang melihat keadaan realita dan menginterprestasi realita untuk berkontribusi pada dunia ini.

\section{Mengembangkan Pendidikan Teologi Sebagai Kontributor dalam Membangkitkan Sikap Kebangsaan}

Pendekatan transformasi visioner pada pendidikan teologi diharapkan memiliki tiga hal yang dapat di kembangkan yaitu: pencarian teologi dunia, usaha membuat teologi relevan, dan dialog antara gereka dengan manusia modern. Ketiga hal tersebut dilakukan untuk mengembangkan pendidikan teologi sebagai kontributor dalam membangkitkan sikap kebangsaan.

Pertama, teologi dunia mengandung arti bahwa Gereja (organisme) bersama dunia, bukan Gereja menundukan dunia, karena abad 21 sekarang ini terjadi ekspansi yang besar pada ilmu pengetahuan dan teknologi, usaha manusia untuk menundukan ekonomi dunia sehingga membuat agama (khususnya Kristen) menjadi profan. Oleh sebab itu, Gereja melalui ajaran - ajaranya harus bersama dengan dunia untuk menganalisis dan memberi jawaban kepada dunia melalui keilmuannya. Evolusi dunia, melalui dan didalam manusia, adalah pesan yang terdalam di Kerajaan Allah. ${ }^{26}$ Dualisme natur - anugerah dapat digantikan dengan pastoral dan kebenaran teologi anugerah didalam naturnya. Oleh sebab itu, sosiologi dapat membantu teologi dalam mendeskripsikan bagaimana proses evolusi dunia terjadi. Sosiologi Agama juga menujukan fenomena modern dari industrialisasi dan urbanisasi, sehingga para ahli teologi mengembangkan aksi tentang penciptaan dan berusaha menemukan aspek - aspek misteri tentang Allah. Oleh karena itu, pendidikan teologi memberikan jawaban bersama dunia bagi manusia serta memberikan solusi dalam membangkitkan sikap kebangsaan untuk memberantas kemiskinan, terorisme, serta diskriminasi.

Kedua, dengan menfokuskan pada rencana Allah untuk dunia ini, maka para teolog melalui penelitian teologi memberikan manfaat kepada manusia modern. Dalam prosesnya, para ahli teologi menemukan bahwa sosiologi dapat menyediakan data - data yang objektif dan sistematik pada fenomena sosial. Faktanya sosiologi dapat membantu dan menilai mana data yang relevan dan mana yang tidak bahkan memberikan sumbangsih pada kenyataan yang sebenarnya, sehingga pendidikan teologi memberikan kontribusi dalam meningkatkan sikap

${ }^{26}$ Halim Wiryadinata, "A Theological Implication of 'Humility' in Mark 10: 13-16 from the Perspective of the Parable of the Kingdom of God," EPIGRAPHE: Jurnal Teologi dan Pelayanan Kristiani 2, no. 2 (2019): 83. 
kebangsaan sebagai bentuk keilmuan dalam mendidik manusia sebagai kapital, bukan cost. Jika pendidikan teologi membentuk manusia sebagai kapital, maka manusia bersama dunia melakukan transformasi visioner untuk membangkitkan sikap kebangsaan dalam memberantas kemiskinan, terorisme serta diskriminasi.

Ketiga, perubahan sosial pada abad ini selalu dihubungkan dengan spirtualitas Kristen agar relevan dengan dunia, maka sosiologi membantu pendidikan teologi untuk mendeskripsikan, mendefinisikan dan menginterpretasikan event dan fenomena disekitar organisme. Dalam prosesnya, sosiologi sebenarnya membantu para ahli teologi melalui pendidikan teologi untuk berdialog dengan dunia, Gereja dan dunia. ${ }^{27}$ Gereja secara universal sebenarnya memiliki dimensi sosial saat dilihat melalui pendekatan sosiologi, sedangkan dunia itu sendiri mempunyai arti yang dapat dimengerti oleh teologi. Oleh sebab itu, sosiologi dan teologi saling membantu untuk meningkatkan sikap kebangsaan dalam melakukan perubahan sosial. Realita dunia disikapi oleh pendidikan teologi dengan inter - displin keilmuan untuk mendapatkan jawab dan solusi bagi perubahan sosial.

\section{KESIMPULAN}

Pendidikan teologi diberikan kesempatan untuk merefleksi diri dalam menyikapi pembangunan baik dari pembentukan manusia, penelitian serta pengabdian kepada masyrakat untuk membangkitkan sikap kebangsaan. Pendidikan teologi harus mampu memberikan jawaban bagi permasalahan dunia, bukan hanya sebagai ilmu untuk mengkritik dunia, karena pendidikan teologi bersama dunia memahami realita dunia itu sendiri.

Keilmuan teologi juga harus mampu melakukan inter - displin atau intersubjectivity dengan keilmuan lainnya, seperti sosiologi agama, untuk mendapatkan consensus dari sebuah dialog dalam memahami realita bangsa. Ilmu yang mampu berdialog dengan ilmu lainnya, maka ilmu tersebut dapat memberikan sumbangsih pada kebutuhan masyarakat dan bangsa. Teologi dalam ranah pendidikan memiliki kesempatan yang luas untuk melakukan penelitian dan pengabdian kepada masyarakat luas sebagai sumbangsih bagi kebutuhan bangsa dan membangun sikap kebangsaan.

Keilmuan teologi juga harus menghapus paradigma sebagai pendidikan yang berfokus pada kesejahteraan umat pada tataran dan aras keselamatan jiwa bagi Kerajaan Surga, tetapi keilmuan teologi melalui pendidikan teologi harus mampu berpijak pada ranah sosial. Berpijaknya pendidikann teologi diranah sosial akan memberikan kesempatan luas dalam meningkatkan kegunaan ilmu teologi bagi bangsa, masyarakat maupun individu. Berpijaknya keilmuan teologi pada ranah realita sosial bukan memiliki pemahaman menjadi sekularisasi, tetapi menempatkan keilmuan teologi menjadi paradigma keilmuan yang berkontribusi bagi masyarkaat, bangsa dan individu.

Pendidikan teologi, akhirnya, harus berpijak pada ranah sosial untuk dapat memberikan jawaban dan solusi bagi kemaslahatan dunia melalui terobosan - terobosan dalam membangun manusia (kapital) sebagai kontributor dalam membangkitkan cinta bangsa sebagai bentuk pendekatan transformasi visioner. Membangun manusia (kapital) yang visioner artinya memberikan jawaban langsung berpijaknya pendidikan teologi bagi masalah sosial.

${ }^{27}$ Halim Wiryadinata, "Religious Human Resources Management: Perichoresis to Manage or to Be Managed?," Khazanah Theologia (2020). 


\section{REFERENSI}

Adi, Suwarto. Jalan Licin Penelitian Lapangan (Menggabungkan Antropologi Dan Teologi). Salatiga, 2019.

Banawiratma, J. B., dan Muller, J. Berteologi Sosial Lintas Ilmu. Yogyakarta: Kanisius, 1993.

Banawiratma, J. B. 10 Agenda Pastoral Transformatif. Yogyakarta: Kanisius, 2002.

Beckwith, Sarah. Shakespeare and the Grammar of Forgiveness. Ithaca New York: Cornell University Press, 2011.

Farrell, Frank B. Empiricism and Theology. How Theology Shaped Twentieth-Century Philosophy, 2019.

Flanagan, Kieran. "Sublime Policing: Sociology and Milbank's City of God." New Blackfriars 73, no. 861 (1992): 333-341.

Furseth, Inger, and Pål Repstad. An Introduction to the Sociology of Religion: Classical and Contemporary Perspectives. Ashgate Publishing Limited. 1st ed. England: Ashgate Publishing Limited, 2013.

Hippo, Augustine of, and Henry Bettlenson. The City of God. The United Kingdom: Penguin Classics, 2004.

Joas, Hans. "Social Theory and the Sacred: A Response to John Milbank." Ethical Perspectives 7, no. 4 (2000): 233-243.

John Milbank. Theology and The Social Theory. 2nd ed. Vol. 66. Oxford: Blackwell Publishing, 2006.

Jun, Chul Min. "The Paradigm Shift of Practical Theology and Theological Practice to Overcome Modernism and Postmodernism." Pacific Science Review 16, no. 2 (2014): 156-166. http://dx.doi.org/10.1016/j.pscr.2014.08.028.

Machiavelli, Niccolo. The Prince. Indianapolis: Hackett Pub. Co, 2008.

Martin, David. "Sociology and Theology: With and Agaisnt the Grain of 'the World" 18, no. 2 (2015): 159-175.

O'Donovan, Oliver. "Preference; Ought." Studies in Christian ethics 2, no. 1 (1990): 80-86.

Talcott Parsons. "Social Science and Theology." In America and the Future of Theology, edited by William A. Beardslee, 136-157. Philadelphia, 1967.

Weber, Max. The Protestant Ethic and the Spirit of Capitalism. The Protestant Ethic and the Spirit of Capitalism, 2005. . The Theory of Social and Economic Organization. New York: Free Press, 1947.

Wheeler, Demian. "American Religious Empiricism and the Possibility of an Ecstatic Naturalist Process Metaphysics." Journal for the Study of Religion, Nature and Culture 8, no. 2 (2014): 156-181.

Wiryadinata, Halim. "A Theological Implication of 'Humility' in Mark 10: 13-16 from the Perspective of the Parable of the Kingdom of God." EPIGRAPHE: Jurnal Teologi dan Pelayanan Kristiani 2, no. 2 (2019): 83.

. "Religious Human Resources Management: Perichoresis to Manage or to Be Managed?" Khazanah Theologia (2020). 